\title{
UMA AVALIAÇÃO DO CONCEITO DE REGENCIA E TRANSITIVIDADE NA TRADIÇÃO GRAMATICAL DO PORTUGUÊS
} Maria Helena de Moura Neves*

Resumo: Estuda-se regência e transitividade na tradição gramatical do português, com o objetivo de verificar os móveis do interesse pelo tema, bem como alguma eventual mudança histórica de direção no modo do tratamento proposto. Analisam-se a conceituação, as relações e as noções de base nesse campo, bem como a visão da propriedade (in)transitiva dos verbos, em correlação com a do estatuto dos complementos. Têm relevância a determinação normativa historicamente documentada da noção de regência e a reação moderna a esse modo de ver. Conclui-se por um condicionamento histórico-social das lições tradicionais, reconhecendo-se, porém, a natural existência de uma direção teórica nas propostas.

Palavras-chave: Regência. Transitividade. Gramática tradicional.

\section{INTRODUÇÃo}

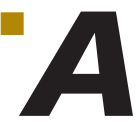

o lado da "concordância", a "regência" é tema de eleição na tradição das gramáticas de língua portuguesa, e essas duas grandes preocupações de tais manuais se unem pelo fato de que constituem territórios férteis para a inclusão de parâmetros avaliativos da construção linguística, um território bastante abonado na tradição da nossa gramática, bem como na gramática ocidental em geral ${ }^{1}$. O nosso pioneiro João de Barros (1540) dirige sua visão de "construção" diretamente para estas "duas coisas": "a concordância e o regimento", e assim define essa última "coisa": "Regimento é quando uma dicção se constrói com outra diversa a ela, por gênero ou por número, caso ou pessoa: somente por uma especial natureza com que obriga e sujeita a seguinte a ser posta em algum dos casos [...]" (BARROS, 1540, p. 30v).

\footnotetext{
Professora Emérita do Programa de Pós-Graduação em Linguística e Língua Portuguesa da Universidade Estadual Paulista "Júlio de Mesquita Filho" (Unesp) - Araraquara - SP - Brasil e do Programa de Pós-Graduação em Letras da Universidade Presbiteriana Mackenzie (UPM) - São Paulo - SP - Brasil. Pesquisadora PQ/CNPq, 1A. E-mail: mhmneves@uol.com.br

1 Nessa última direção se insere o texto de Neves (2010).
} 
Sabemos que a concordância é fato linguístico de superficie, que tem o seu peso mais pelo que possa significar em termos de avalição normativa do que pelo que signifique em termos de avaliação propriamente gramatical dos enunciados. A visão da regência, porém, realmente se liga à explicitação de um fato determinante na produção linguística: a predicação. Exatamente por tais condições, as lições sobre regência que se encontram desenvolvidas nos manuais frequentemente mesclam os dois interesses - a lição de norma prescritiva e a lição gramatical pura -, ficando aberta a nosso exame a avaliação do peso que cada autor gramático confere a cada um deles.

A matéria entra em análise, neste estudo, a partir de lições encontradas em gramáticos, de diferentes épocas, que se costuma classificar como "tradicionais", os quais foram buscados a partir exatamente de 1540, com João de Barros, com a pretensão de verificar os móveis do interesse pelo tema, bem como alguma eventual mudança de direção no modo de tratamento da regência (genericamente: da transitividade verbal no correr do tempo.

Num ou noutro tópico de desenvolvimento desse tema - que não tem a pretensão de estudo exaustivo, mas, pelo contrário traz apenas amostras -, recorre-se a lições de alguns gramáticos da nossa tradição ${ }^{2}$, a seguir citados pela ordem alfabética do sobrenome de citação:

BARBOSA, Jerônimo Soares. Gramática Filosófica da Lingua Portuguesa.

BARROS, João de. Gramática da Língua Portuguesa.

BECHARA, Evanildo. Moderna gramática portuguesa.

BRANDÃO, Cláudio. Sintaxe clássica portuguesa.

CARNEIRO RIBEIRO, Ernesto. Serões gramaticais.

CEGALLA, Domingos Paschoal. Novissima gramática da lingua portuguesa.

CUNHA, Celso. Gramática do português contemporâneo.

CUNHA, Celso. Gramática moderna.

GÓIS, Carlos. Sintaxe de regência.

LOBATO, Antonio José dos Reis. Arte da gramática da lingua portuguesa.

LUFT, Celso. ${ }^{3}$ Gramática resumida.

NOGUEIRA, Júlio. Programa de português. Gramática.

PEREIRA, Eduardo Carlos. Gramática expositiva (Adaptada ao 1ำ, 2ำ e 3 o ano dos ginásios).

PEREIRA, Eduardo Carlos. Gramática expositiva (Curso elementar).

RIBEIRO, João. Gramática portuguesa: 3ำ ano.

RIBEIRO, João. Gramática portuguesa: Curso superior.

ROCHA LIMA, Carlos Henrique. Gramática normativa da lingua portuguesa.

SOUSA DA SILVEIRA, Álvaro Ferdinando. Lições de português.

SOUZA LIMA, Mário Pereira de. Gramática portuguesa.

TORRES, Artur de Almeida. Moderna gramática expositiva da língua portuguesa.

2 Contemplam-se, especificamente, autores de obras publicadas no Brasil, a que se acrescentam, pelas suas especificidades e pela historicidade, João de Barros e Jerônimo Soares Barbosa.

3 Recorri também a seu Dicionário prático de regência verbal (LUFT, 1987). 
Obviamente as generalizações que se fizerem neste texto são ensaísticas, apoiando-se apenas nesse conjunto de referências, sem a qualidade de uma varredura total na história da gramática da língua.

\section{A REGÊNCIA VERBAL}

\section{A conceituação e o estatuto}

A regência, como observei na Introdução, é uma categoria característica da tradição gramatical da língua portuguesa, com presença mais forte nas obras mais antigas, nas quais é bastante comum uma seção denominada "sintaxe de regência” (como em BARBOSA (1822 e em CARNEIRO RIBEIRO (1956 [1890])), embora algumas obras mais recentes, da segunda metade do século $\mathrm{XX}^{4}$, também contemplem uma seção desse tipo (como TORRES (1960 [1959]) e CEGALLA, $1971[1964])^{5}$. Do bastante tradicionalista Carlos Góis (1943) temos toda uma obra dedicada a essa matéria.

Nem sempre a categoria regência vem definida nas gramáticas, e são três os principais "gêneros" (para subsequente diferenciação específica) que lhe são atribuídos nas conceituações encontradas: "relação", como em Souza Lima (1945 [1937], p. 263), Cunha (1970, p. 243), Torres (1960 [1959], p. 177) $)^{6}$; "propriedade", como em Pereira (1907, p. 223, 1956 [1908], p. 132); e "função", como em Luft (1971 [1960], p. 124).

Como se poderá observar na terceira subseção desta seção, em que se apresentam e se comentam as definições, a referência à noção de "complementação", na conceituação de regência, é bastante comum, como em Pereira (1907, p. 223, 1956 [1908], p. 132) e em Cunha (1970, p. 243), assim como a referência a "subordinação”, como em Luft (1971 [1960], p. 124), em Torres (1960 [1959], p. 177) e em Cegalla (1971 [1964], p. 345). Souza Lima (1945 [1937], p. 263) conjuga as duas noções, a de complementação e a de subordinação, assim como Cunha (1970, p, 243), que acrescenta à sua definição a indicação de que "a palavra dependente denomina-se regida, e o termo a que ela se subordina, regente" (grifo meu).

Sabe-se hoje, dentro dos mais rudimentares princípios da Linguística, que a regência verbal necessariamente se resolve, no terreno puro da gramática da língua, em relação direta com a ativação da estrutura argumental, obviamente, mas essa noção não é explicitada, ou ao menos sugerida nos manuais em geral ${ }^{7}$. Ora, a natureza semântica do núcleo verbal é variável: usando-se, por exemplo, a classificação de Chafe (1979, p. 95-105), os verbos são de ação, processo, ou estado, mas a tradição da gramática de língua portuguesa, quando trata a questão da complementação, tem-se referido aos verbos apenas pela via da expressão de "ação" (como se verá nas duas primeiras subseções da seção seguinte), o

4 Na exposição, faço constar, quando pertinente, a data da 1ạ edição da obra, a fim de que o leitor possa situá-la historicamente, para a devida apreciação dos fatos.

5 E nem sempre o termo regência é apresentado nas gramáticas como introdutor de uma seção específica. Ele não está, por exemplo, em Sousa da Silveira (1952), e, em alguns outros autores, ele é usado apenas para encabeçar a explicação de casos particulares (BECHARA, 1999, em que não se define a categoria), ou para encabeçar a apresentação de exercícios sobre o tema (NOGUEIRA, 1944).

6 Torres (1960, p. 177) não traz, propriamente, uma definição da categoria, mas fala em "relações de regência" ("pela posição, pela preposição e pelas palavras subordinantes").

7 Excetue-se a versão mais recente de Bechara (1999), que traz entremeadas determinadas lições da Linguística. No caso específico, a obra tem uma subseção denominada "Termos argumentais e não argumentais" (p. 412-413). 
que de certo modo perturba a interpretação das proposições que se fazem. Assim, só oferecendo um exemplo, cite-se Góis (1943, p. 70), para quem verbo transitivo é "aquele cuja ação se projeta do sujeito para recair sobre outro indivíduo", e verbo intransitivo "é aquele cuja ação não passa além do sujeito" e "que por si só exprime sentido completo" (grifos meus).

Em seu dicionário de regência verbal, Luft (1987, p. 13) soube bem marcar que "os traços semânticos do verbo é que preveem a presença ou a ausência de complementos", e que, portanto, "a semântica dita a regência", o que bem mostra a necessidade de uma compreensão dos componentes naturalmente atuantes no processo.

\section{As relações}

O primeiro ponto a examinar é, naturalmente, o conceito de regência que dirige as propostas sobre a questão, e já em obras bastante antigas se ilustram duas indicações que são as mais relevantes na explicitação das relações de regência: a noção de determinação e a de dependência.

Em Jerônimo Soares Barbosa (1822, p. 392s) está uma concepção muito particular, que atrela as relações de regência à noção de determinação ${ }^{8}$. Depois de declarar que "reger é determinar, e demandar alguma coisa" (p. 392), ele explica que há palavras cuja significação é intransitiva, ou absoluta, e que "nada determinam” (p. 393), mas há outras cuja significação é transitiva, ou relativa, e que "por isso requerem se lhes complete, para não ficar suspensa" (p. 392): os verbos ativos transitivos, os adjetivos do mesmo tipo, as preposições. O resumo é que, "assim como a relação de identidade entre as ideias é o fundamento da sintaxe de concordância, assim a relação de determinação entre as mesmas é o fundamento da sintaxe de regência" (p. 392-393). Diz o gramático que onde há regência necessariamente há de haver "partes regentes e partes regidas": as partes regentes propriamente ditas são apenas o adjetivo de significação relativa (classe em que se inclui o verbo ativo e o advérbio de significação relativa, sendo exemplos, respectivamente, dependente, depender e dependentemente) e a preposição; as partes regidas, por sua vez, podem ser todas as que compõem a oração (p. 394).

Por outro lado, em Ernesto Carneiro Ribeiro (1956 [1890]) está a definição de regência por recurso à noção de dependência. A obra indica a regência como "a dependência das várias partes da proposição, cujo sentido é determinado por uma delas, por meio de adjetivos, advérbios, verbos e preposição" (p. 684). A partir daí, distinguem-se as partes regentes (que se representam por essas quatro classes discriminadas) e as partes regidas. Das primeiras se diz que pedem um complemento, e das outras se diz que ficam sob a dependência da parte regente. Essa noção de "dependência" é a mais recorrente entre os gramáticos que abrigam a regência em suas lições, como se verá no desenvolvimento subsequente deste estudo.

Geralmente o conjunto de partes regentes é visto como composto daquelas quatro classes que aqui vêm sendo citadas (adjetivo, advérbio, verbo e preposição), mas Lobato (1770, p. 199) reduz esse conjunto a apenas "duas partes ou palavras que regem caso, que são o verbo ativo e a preposição". Por seu lado, Cegalla (1971 [1964]), um dos poucos autores mais recentes que abriga formal-

8 Por outro lado, para as relações de concordância, também na mesma seção ele considera como fundamento a "identidade". 
mente a "sintaxe de regência" (como indiquei na primeira subseção desta seção), encaminha já de início a apreciação para uma regência verbal e uma nominal, e apenas se refere, como "termos regentes" (p. 345), de um lado, ao verbo ("regência verbal"), e, de outro, ao substantivo e ao adjetivo ("regência nominal"). Essa classificação de regência é a direção geral das gramáticas tradicionais mais recentes, especialmente guiadas pelas propostas da Nomenclatura gramatical brasileira oficial.

A regência verbal é o tema deste texto.

\section{O campo das noções}

Como já lembrei na primeira subseção desta seção, a explicitação da noção de regência vinculada determinantemente à noção de complementação é uma constante na tradição gramatical brasileira. Facilmente se percebe, como também já sugerido aqui, que esse campo tem dupla inserção - na sintaxe e na semântica -, entretanto a tradição gramatical se rendeu mais à explicitação feita por via das significações, por outro lado alocando essa explicitação no compartimento nomeado como de sintaxe.

Pereira (1907, 1956 [1908], 1935 [1915]) fala em "dependência”, mas a definição se faz apenas por via de uma noção de "sentido", embora o tratamento do tema "regência" (que se coloca no "grupo lógico" da subordinação) venha com uma subespecificação que acentua sua ligação com a gramática ("regência gramatical"): "Regência gramatical é a propriedade de terem certas palavras outras palavras sob sua dependência, para lhes completar ou limitar o sentido" (PEREIRA, 1907, p. 223, 1956, p. 132); ou: “[...] outras palavras sob sua dependência, que lhes explanam o sentido" (PEREIRA, 1935 [1915], p. 321). Completa o gramático, logo a seguir: "Donde se vê que as palavras regidas são complementos das regentes, estas se dizem subordinantes, e aquelas subordinadas". A subordinação, ou regência, se expressa pela preposição, e, por sua vez, a preposição rege o substantivo, que é, por isso, o seu complemento.

Em Souza Lima (1945 [1937], p. 262) pode-se encontrar uma definição de regência que, embora fincada na interpretação semântica do verbo, também se marca fortemente pela indicação da relação subordinativa: regência é "a relação entre um complemento e a palavra à qual se subordina, completando-lhe o sentido". Do ponto de vista sintático, essas relações de regência são explicitadas pelo gramático, segundo a marcação feita pelos nexos sintáticos ou pela não necessidade deles: pelas preposições, ligando palavras, e pelas conjunções subordinativas, ligando proposições, mas, também, sem essa marcação de conectivo exterior, pela simples posição, ordem ou colocação de certos termos.

Cegalla (1971 [1964], p. 345) foge de uma vinculação maior com o significado quando define regência como "o modo pelo qual um termo rege outro que o complementa"), mas não quando define os "termos regentes ou subordinantes" como aqueles que "reclamam outros (termos regidos ou subordinados) que lhes completem o sentido". Cunha (1970, p. 243), por seu lado, prende-se apenas à complementação na sua definição de regência como aquela "relação necessária que se estabelece entre duas palavras, uma das quais serve de complemento a outra".

Luft (1971 [1960], p. 124) oferece um exemplo acabado de definição puramente sintática de regência, embora ele já tenha sido aqui citado exatamente 
como aquele que soube reconhecer que "a semântica dita a regência" (LUFT, 1987, p. 13): "Regência é a função subordinativa de termos principais (regentes) sobre termos dependentes (regidos)". E assim ele arremata: "É este o princípio que governa a estrutura da frase, lhe dá conexão, equilíbrio e perspectiva”. Nessa visão de regência firmemente ligada à organização predicativa, o autor, declarando basear-se em sistematização de Gama Cury (1960, § 140), especifica os estabelecedores principais da regência: a concordância dos termos regidos com os regentes; as preposições; as conjunções subordinativas; os pronomes relativos; a posição dos termos na oração.

Menção especial deve ser feita a Barbosa (1822, p. 393), que, no início do século XIX, limita a indicação de "transitivos" aos verbos já classificados como "ativos", com isso legitimando a indicação de que esses verbos "requerem depois de si um objeto em que passe a sua ação".

\section{OS ELEMENTOS ENVOLVIDOS NA REGÊNCIA VERBAL}

\section{O verbo}

A classificação dos verbos em relação à regência - transitivos e intransitivos - é a mesma classificação que se aplica às próprias orações, embora na tradição gramatical preferentemente os verbos venham recebendo essas denominações.

A propriedade de (in)transitividade, inerente ao funcionamento predicativo, por isso mesmo inerentemente ligada ao funcionamento verbal, constitui "um fenômeno complexo que envolve componentes sintáticos, semânticos e pragmáticos" que "pode ser definido em termos desses três principais traços" (GIVÓN, 1993, p. 99, tradução minha). Acrescenta o autor que "cada um desses traços tem foco nas propriedades ou do sujeito, ou do objeto, ou do verbo da oração", e, "tomados juntos, os três definem o protótipo do semanticamente transitivo" 9 . Assim definido, o protótipo da oração transitiva teria: 1. semanticamente, agentividade (um agente deliberadamente ativo), afetabilidade (um paciente concreto, visivel) e perfectividade (evento limitado, terminado, fast-changing; que se dá em tempo real); 2. sintaticamente, um verbo com objeto direto.

Também merece apreciação, hoje, a proposta de Hopper e Thompson (1980) sobre o modo como as orações transitivas se codificam sintagmaticamente (sintaxe) segundo as propriedades de um agente e de um participante afetado (semântica), e até de como a transitividade depende da função da oração no todo do discurso, por exemplo em ligação com o fluxo de informação (pragmática).

Não seria necessário dizer, porém, que esse não é o modo de avaliação tradicional, a qual, embora percebendo uma natureza sintático-semântica no processo, não conduz a explicitação de modo que esses dois componentes sejam sequer suspeitados. Frequentemente se conduz a questão sobre base puramente semântica, embora intrigantemente inserida em compartimentos abertos e rotulados como pertencentes ao campo da sintaxe (conforme já indicado no final da segunda subseção da primeira seção). Nesse particular merece nova menção Luft (1987, p. 13), para quem "a noção de que a semântica dita a sintaxe [...] é fundamental para compreender mudanças e variações de regência verbal”. 
Nas diversas seções deste texto pode ser visto que, quanto à propriedade da (in)transitividade, os gramáticos tradicionais geralmente optam, para o(s) verbo(s), por uma definição assentada nos significados. Volte-se apenas a uma definição, a de Góis (1943, p. 74), de verbo transitivo como "aquele cuja ação se projeta do sujeito para o objeto, que é, portanto, o seu ponto de descarga", e de verbo intransitivo como "aquele cuja accão não passa além do sujeito", aquele "que por si só exprime sentido completo" (grifos meus).

Bechara (1977, p. 205) faz intervir fortemente a significação na definição de verbo intransitivo, mas não por via do recurso à noção de ação: intransitivo "é o verbo que não precisa de complemento para integrar seu sentido, isto é, o verbo que basta a si mesmo; por outro lado, na definição de verbo transitivo, o recurso à noção de integração deixa o campo das significações para fixar-se apenas no processo de predicação: transitivo "é o verbo que necessita de complemento que integre a sua predicação”. Entretanto, em Bechara (1999, p. 415), essas duas categorias de verbo não são contempladas nomeadamente para estudo, ou nem mesmo são consideradas, já que o que se afirma é que "um mesmo verbo pode ser usado transitiva ou intransitivamente"; guiada pela noção de estrutura argumental, a lição indica que os verbos que necessitam de "delimitadores semânticos" ("que se chamam argumentos ou complementos verbais") são os que "recebem o nome de transitivos".

A visão histórica nos mostra que já em João de Barros (1540) está a indicação de que há verbos (os verbos "pessoais", ou seja, os que têm número e pessoa) que podem, ou não, passar a sua "ação" a outra "coisa". Diz o gramático: "Os que passam chamam-lhe os latinos transitivos. Que quer dizer passadores: como, eu amo a ciência, a ação do qual verbo, amo, passa na ciência” (BARROS, 1540, p. 31v).

Para a explicitação desses diversos "regimentos", as indicações de Barros (1540), segundo o que era comum na época, vêm absolutamente decalcadas da gramática latina, ou seja, dirigidas pela noção de caso morfossintático: dos verbos "passadores", diz ele que

[...] têm diversos regimentos, porque uns regem genitivo, outros dativo, outros acusativo, outros dativo e acusativo [....]. Os verbos que regem acusativo propriamente são os transitivos: como amo a virtude, aborreço o vício, leio os livros, aprendo ciência, ouço gramática e ganho honra [....] (BARROS, 1540, p. 31v).

Dos verbos impessoais (que são os que não têm números e pessoas e se conjugam pelas terceiras), quanto ao "regimento", diz o gramático que "têm natureza que querem dativo, e depois de si um verbo do modo infinito: o qual rege o caso de seu verbo por semelhante exemplo, A mim coube dar doutrina [....]" (BARROS, 1540, p. 31v).

Merece observação a posição de Souza Lima (1945 [1937]), que, embora definindo regência por via de uma explicitação semântica (ver a segunda subseção da primeira seção) e embora falando em "significação" transitiva e "significação" intransitiva dos verbos (p. 202), quando trata a classe verbal a que chama "neutra" (a dos verbos intransitivos, que, "não tendo objeto direto que seja o paciente da ação, não são propriamente ativos nem passivos"), ressalta, citando Bello (1995, § 741, tradução minha), que

[...] a ação e a paixão gramaticais nada têm que ver com o significado, mas sim com a construção dos verbos. Há-os, pois, que significam verdadeiras ações $e$ 
apesar disso são neutros, como pelejar, e há-os que denotam verdadeira paixão e apesar disso são ativos, como padecer. ${ }^{10}$

Afinal, cabe observar que, apesar de a transitividade verbal resolver-se apenas nos seus dois polos (positivo e negativo), a classificação tradicional mais geral dos verbos, quanto à complementação, é tripartite, porque aos verbos transitivos e intransitivos se acrescentam os de ligação. Uma classificação que contempla mais especificamente ainda os diferentes tipos de complementação é a de Pereira (1956 [1908], p. 96): "transitivo", "intransitivo", "relativo", "transitivo-relativo" e "de ligação", devendo-se observar, entretanto, que na primeira edição da obra (PEREIRA, 1907, p. 136), os verbos de ligação não entravam nessa classificação dos verbos "quanto ao complemento", o que, na verdade, pode ser considerado mais exato.

\section{Os complementos}

A mesma direção semântica impressa à apreciação dos verbos quanto à transitividade é encontrada no geral das propostas tradicionais de conceituação dos complementos verbais. Por exemplo, são definições de base semântica para os complementos as que se encontram em Souza Lima (1945 [1937], p. 48-49, grifo meu), para quem objeto direto "é o que representa o paciente ou o resultado da ação do verbo ativo", em Rocha Lima (1974 [1957], p. 212, grifo meu), para quem objeto direto é o "complemento que, na voz ativa, representa o paciente da ação verbal"), e em Sousa da Silveira (1952 [1923], p. 42, grifo meu), para quem objeto direto "representa a pessoa ou coisa que recebe a ação expressa pelo verbo e praticada pelo sujeito, ou que é o produto daquela ação".

A avaliação que aqui trago poderia ser considerada desmentida, se levado em conta o fato de que a subclassificação dos complementos dos verbos "transitivos" se faz, regularmente, por via da existência, ou não, de preposição introdutória. O próprio objeto direto (ou complemento direto), que, caracteristicamente, não é introduzido por preposição, em geral vem caracterizado exatamente por essa propriedade negativa, como em Ribeiro (1933 [1889], p. 234): "O complemento direto, quando é substantivo, não vem regido de preposição, exceto quanto aos nomes próprios (ou personificados)". Entretanto, esse tipo de definição, que, em si, apenas se refere ao modo de construção, não significa necessariamente que a noção deixe de estar semanticamente embasada. Ocorre que a definição de "complemento direto" que precede a indicação diz que esse complemento "é o nome do objeto indicado ou produzido pela ação do verbo" (RIBEIRO, 1933 [1889], p. 233). E, em Ribeiro (1933 [1889], p. 215), também está a definição puramente semântica de "objeto" como "a palavra em que se emprega a ação do verbo".

Ilustre-se o caso, ainda, com Barbosa (1822), que tem a seguinte explicação: alguns complementos objetivos levam preposição, e outros não, porque alguns verbos ativos têm significação ativa e relativa ao mesmo tempo; sendo assim, eles pedem um objeto e um termo (ou seja, um objeto direto e um indireto); como

10 Trecho total original: "Extraño parecerá que se considere a padecer como verbo activo, siendo la idea que con él significamos tan opuesta a lo que se llama vulgarmente acción. Pero es necesario tener entendido que la acción y pasión gramaticales no tienen que ver con el significado sino con la construcción de los verbos. Los hay, pues, que significan verdaderas acciones, y que, sin embargo, son neutros, como pelear; y los hay que denotan verdadera pasión, y que, sin embargo, son activos, como padecer; consistiendo todo en que a los primeros no podemos darles regularmente complementos acusativos como lo hacemos de ordinario con los otros: padeces trabajos, dolores, calamidades" (BELLO, 1995, p. 213). 
o objeto será de coisas, a preposição a fica reservada para o termo, que, geralmente, é pessoa. Partindo da proposição de que as palavras regentes expressam uma ação, uma relação, ou ambas, o gramático prevê que as primeiras devem ter um complemento objetivo; as segundas, um complemento terminativo; e as terceiras, os dois. Portanto, para o gramático, se o verbo expressa ação, seu complemento será o objeto direto, e se o verbo tem significação relativa, seu complemento será o objeto indireto, proposição que é bastante original, e pertinente, já que prende a existência da preposição à noção semântica expressa pelo verbo.

Ao final, particularmente ilustradora de uma interpretação da complementação verbal apenas ligada a significado, e já no século XX, é a indicação de Nogueira (1944, p. 18) de que o objeto direto é o termo que tem de ser usado quando "a significação do verbo não basta para dizer tudo".

\section{A DETERMinAÇÃo NORMATIVA DA NOÇÃo DE REGÊNCIA}

O território da regência é claramente normativo nas gramáticas tradicionais, só sendo superado, quanto à rígida posição prescritivista, para o território da concordância, cuja transgressão - todos sabemos - é a mais discriminada no julgamento social do desempenho linguístico.

\section{A normatividade historicamente documentada}

Comecemos por Brandão (1963), de quem se pode dizer, sem medo de errar, que, na segunda metade do século XX, serve para ilustrar a categoria dos gramáticos normativos. Seu exemplário é geralmente baseado em autores bem anteriores à sua época, o que já revela conservadorismo, mas mesmo esses grandes escritores podem ter suas construções condenadas, a qualquer discrepância das lições da gramática tradicional que o autor note: por exemplo, o uso do pronome reto ele como objeto direto tem exemplos (embora raríssimos) em escritores, mas seu uso é considerado plebeu por Brandão (1963, p. 65), que, quando tenta reproduzir, em algumas de suas personagens, o falar plebeu do Brasil, imita essa sintaxe.

Nesse mesmo terreno navega Carlos Góis (1943, p. 148-152), que classifica como "solecismo" de regência verbal, por exemplo, o uso do pronome pessoal de objeto indireto the pelo de objeto direto o, a (eu the vi por eu ovi), e o uso do pronome pessoal ele como objeto (vi ele por vi-o), construção que constitui, segundo "os gramáticos portugueses", um "brasileirismo" inerente ao falar próprio das "classes incultas" no Brasil. O gramático vai a escritores antigos, cronistas portugueses do século XVI, que - diferentemente dos escritores clássicos - registram, embora raramente, esse tipo de construção (como em Fernão Lopes: El-rei degredou ele e os filhos).

Na mesma época Souza Lima (1945 [1937], p. 263) apresenta uma lista de verbos com a sua regência, assim anunciando-os: "para melhor estudar a regência dos verbos, dão-se aqui exemplos extraídos de bons escritores". Para dar a seus leitores modelos de uso quanto à regência verbal (ver terceira subseção da segunda seção), o gramático apresenta uma lista de verbos, com especificação de sua regência também a partir de "exemplos extraídos de bons escritores" (SOUZA LIMA, 1945 [1937], p. 263, grifo meu), numa extensão de 47 páginas 
(páginas 264 a 310). Torres (1960 [1959], p. 178) prefere anunciar o que chama de "regências interessantes", em uma lista que também se estende por várias páginas (página 179 a 193). Cegalla (1971 [1964]) apenas oferece como "da língua atual" os "verbos com suas regências e acepções", abonados com exemplos de escritores, ou criados pelo gramático (páginas 351 a 365). Rocha Lima (1974 [1957]) se limita a abrir uma seção denominada "Regência de alguns verbos" (páginas 385 a 416).

Recuando mais no tempo, vê-se, no final do século XIX, Carneiro Ribeiro (1956 [1890]) fixado fortemente às normas de regência, mas fazendo-o em nome da elegância e da beleza da lingua, o que se pode considerar ainda mais elitista, porque revela nenhuma preocupação com os usos dos falantes comuns, e, portanto, com a norma ligada a estatuto social (a qual tem sua legitimidade, dada a inegável função social da linguagem. O gramático tem a língua como não homogênea, reconhece as variações, mas valoriza especialmente a variante dos bons escritores e dos gramáticos, não a do usuário não envolvido com as letras.

Mesmo Barbosa (1822), que, no século XIX, faz uma gramática muito menos pautada pelos mais rígidos cânones tradicionais - faz uma gramática "filosófica" -, não deixa de apontar os empregos corretos das regências tradicionalmente abonadas. Entretanto, dele vem uma lição exemplar: na contramão daquilo que, mais tarde, se tornou quase uma praxe nos manuais - especialmente nos de orientação escolar -, julga o gramático que é desnecessária a apresentação de uma longa lista de nomes e verbos com as respectivas preposições. Segundo ele, para saber as preposições regidas por essas palavras, basta refletir em sua significação, consultar o uso vivo, e, na dúvida, os dicionários de língua.

\section{O contramovimento moderno}

Seria fácil mostrar, partindo de linguistas, o movimento de reação a esse modo de ver a ativação da regência pelos falantes exclusivamente com a pauta da normatividade. Entretanto, essa não é a proposta deste texto, que vai justamente ao modo de apresentação da regência nas "gramáticas" tradicionais da língua, e, nesta subseção, seleciono, quanto a esse contramovimento, os dois gramáticos que atuaram com maior relevância na segunda metade do século XX, Celso Cunha e Evanildo Bechara. A esses acrescentarei, ainda, Celso Luft ${ }^{11}$, de posições muito seguras, e nome importante nesse "contramovimento".

Na sua Gramática do português contemporâneo, Celso Cunha (1975) diz que seu objetivo é apresentar as características do português contemporâneo em sua forma culta, sem deixar, porém, de incluir o interesse pelos fatos da linguagem coloquial. Ele declara que a exemplificação é declaradamente de escritores brasileiros e portugueses do Romantismo para cá, dando uma situação privilegiada aos autores de nossos dias. Esse registro explícito de uma atenção ao uso contemporâneo da língua não elimina a atenção primeira à norma e à correção, que o autor considera indispensáveis a uma gramática descritiva da língua culta. $\mathrm{O}$ gramático se socorre da visão de um linguista, Eugenio Coseriu, para quem o conceito linguístico ideal de norma corresponde ao que já se disse e tradicionalmente se diz em uma determinada comunidade, resultando à conclusão de que o que entra em causa é o que é "normal" na sociedade, não o que é "normatizado".

11 As primeiras edições das gramáticas desses três autores aqui citadas datam dos anos 1960 a 1970. 
A mesma diretriz tem Bechara (1999), que cita mais de uma dezena de obras de Coseriu. O gramático deixa sempre revelada sua célebre visão de "exemplaridade", contraposta à noção de correção (BECHARA, 1999, p. 51-52), em vários casos particulares de explicitação do modo de construir as relações de regência na língua. E disso trago dois exemplos. Quando estuda o uso da preposição para introduzindo uma oração objetiva direta (como em pedir que algo aconteça), diz Bechara (1999, p. 566-567) que muitos gramáticos consideram errada essa construção, argumentando que o objeto direto oracional não pode vir introduzido por preposição. Ele considera o argumento muito fraco, e objeta que essa construção tem penetrado muito na linguagem das pessoas cultas, explicando - como uma justificativa para a construção condenada - que esse uso da preposição se deve ao fato de que, na linguagem coloquial, as ideias de pedir que algo aconteça e de trabalhar para que algo aconteça se aproximam, passando-se, então, ao uso da preposição para introduzir a oração que seria objeto direto de pedir. Por outro lado, ele observa que esse novo modo de expressão pode trazer ambiguidades, pois, em uma oração como "Antônio pediu a José para sair", não se sabe de imediato se quem sai é Antônio ou José. Salienta que esse uso do para introduzindo a oração objetiva direta pode servir para denotar interesse ou insistência no pedido, como ocorre em cumprir com o dever ao lado de cumprir o dever. Outro caso de tratamento de regência em que se pode bem ver a posição de Bechara (1999, p. 569-570) quanto à normatividade rígida é aquele em que há complemento relacionado a regências diferentes, caso em que o rigor gramatical exige que não se dê complemento comum aos diferentes termos regentes. Assim, não se deve dizer Entrei e sai de casa, mas Entrei em casa e dela sai, pois entrar pede a preposição em e sair pede a preposição de. No entanto, diz o gramático (recorrendo a dois exemplos de um autor clássico modelar, Alexandre Herculano):

Ao gênio de nossa língua, porém, não repugnam tais fórmulas abreviadas de dizer, principalmente quando vêm dar à expressão uma agradável concisão que o giro gramatical correto nem sempre conhece:

Tenho-o visto entrar e sair do Colégio de São Paulo (AH.5, I, 154) (BECHARA, 1999, p. 570).

E, ainda, segundo Bechara (1999, p. 570), "salvo as situações de ênfase e de encarecimento semântico de cada preposição", "a língua dá preferência às construções abreviadas que a gramática insiste em condenar, sem, contudo, obter grandes vitórias". Ora, nos dois exemplos aqui trazidos pode-se dizer que há em Bechara (1999) grande boa vontade com a flexibilidade das normas, com recurso, porém, à exemplaridade de modelos, e sem concessão ao que discrepa das regras mas não justifica proveito no uso, ou não oferece exemplo edificante de uso.

Encerro com o Dicionário prático de regência verbal (LUFT, 1987), em que o autor cita Nascentes (1960, p. 18) para afirmar lucidamente que "a regência, como tudo na língua [...], não é imutável", não se podendo "seguir hoje exatamente a mesma regência que seguiam os clássicos", pois "cada época tem sua regência".

\section{ConClusão}

Duas direções me parece evidente que podem ser seguidas no rescaldo destas reflexões sobre o modo de ver a chamada "regência verbal", ou seja, sobre o 
modo de ver a construção dos enunciados, no que diz respeito ao estabelecimento da sua (in)transitivização, ou - já numa visão cientificamente trabalhada -, no que diz respeito à construção da sua estrutura argumental.

De um lado, há a ver que a "técnica" envolvida na elaboração de manuais de gramática implica, sempre, uma tomada de direção teórica (pré-científica que seja), que assente a visão conceitual que estará na base das "descrições" e/ou das interpretações da língua objeto. No caso particular deste estudo, facilmente se capta a complexidade do fato em análise, o qual constitui o cerne da produção de linguagem: trata-se da construção das "predicações" da língua, que constituem o suporte gramatical central das "proposições" que os atos de fala produzem no discurso.

De outro lado, como em toda avaliação da gramática tradicional que se empreenda, fica evidente a existência de condicionantes históricos tanto para a natureza intrinsecamente gramatical das lições como para a sua natureza sociocultural. Não poderia ser diferente no caso de um compartimento tão sensível à produção de normas comportamentais como o da "regência" (termo, em si, de peso normativo, ligado a uma "determinação"), ou "transitividade" (termo, em si, de peso teórico, embora tenha nascido no bojo das propostas em si determinativas, como a de "regência"). Obviamente o primeiro é bem do gosto dos autores que produziram suas obras em um tempo em que a sociedade esperava das gramáticas nada mais do que regras de conduta para a linguagem, muito especificamente para a lingua "regida" prescritivamente.

\section{AN EVALUATION OF THE CONCEPT OF PATTERNS OF COMPLEMENTATION AND TRANSITIVITY in Portuguese grammatical tradition}

Abstract: In this paper, we study patterns of complementation as well as transitivity in Portuguese grammatical tradition aiming at verifying the motor of interest toward these subjects as well as eventual historic changes in the direction of the treatment they have been given. We analyze the concepts, the relations and the grounding notions in this camp, as well as the (in)transitive property of verbs in correlation with the status of their complements. Historically documented normative determinations of the notion of complementation and the modern reactions to such a view are relevant to our examination. Our conclusion moves toward a socio-historic conditioning of traditional lessons, acknowledging, however, the natural existence of theoretical directions in the proposals.

Keywords: Patterns of complementation. Transitivity. Traditional grammar.

\section{REFERÊNCIAS}

BARBOSA, J. S. Gramática filosófica da língua portuguesa ou princípios de gramática geral aplicados à nossa linguagem. 5. ed. Lisboa: Academia Real das Ciências, 1822 .

BARROS, J. de. Gramática da lingua portuguesa. Lisboa: Ludovido Rotorigiu, 1540.

BARROS, J. de. Gramática da lingua portuguesa. Lisboa: Faculdade de Letras da Universidade de Lisboa, 1971 [1540]. 
BECHARA, E. Moderna gramática portuguesa. 22. ed. São Paulo: Companhia Editora Nacional, 1977 [1961].

BECHARA, E. Moderna gramática portuguesa. 37. ed. Rio de Janeiro: Lucerna, 1999 [1961].

BELLO, A. Gramática: gramática de la lengua castellana destinada al uso de los americanos. In: BELLO, A. Obras completas. Tomo Cuarto. 3. ed. Caracas: La Casa de Bello, 1995.

BRANDÃO, C. Sintaxe clássica portuguesa. Belo Horizonte: Imprensa da Universidade de Minas Gerais, 1963.

CARNEIRO RIBEIRO, E. Serões gramaticais ou Nova gramática portuguesa. 6. ed. Bahia: Progresso, 1956 [1890].

CEGALLA, D. P. Novíssima gramática da língua portuguesa. 12. ed. São Paulo: Nacional, 1971 [1964].

CHAFE, W. Significado e estrutura linguística. Tradução M. H. M. Neves et al. São Paulo: Livros Técnicos e Científicos, 1979 (1970].

CUNHA, C. Gramática moderna. 2. ed. Belo Horizonte: Bernardo Álvares, 1970 [1970].

CUNHA, C. Gramática do português contemporâneo. Belo Horizonte: Bernardo Álvares, 1975 [1970].

GAMA CURY, A. Pequena gramática. Rio de Janeiro: Agir, 1960.

GIVÓN, T. The pragmatics of de-transitive voice: Functional and typological aspects of inversion. In: GIVÓN, T. Voice and inversion. Amsterdam; Philadelphia: John Benjamins, 1933, p. 3-46.

GÓIS, C. Sintaxe de regência. 5. ed. Rio de Janeiro; São Paulo; Belo Horizonte: Gráfica Sauer, 1943.

HOPPER, P. J.; THOMPSON, S. Transitivity in grammar and discourse. Language, v. 56, n. 2, p. 251-299, 1980.

LOBATO, A. J. dos R. Arte da gramática da lingua portuguesa. Lisboa: Régia Oficina Tipografica, 1770.

LUFT, C. P. Gramática resumida. 2. ed. Porto Alegre: Globo, 1971 [1960].

LUFT, C. P. Dicionário prático de regência verbal. São Paulo: Ática, 1987.

NASCENTES, A. O problema da regência: regência integral e viva. 2. ed. Rio de Janeiro: Freitas Bastos, 1960.

NEVES, M. H. de M. Uma reflexão sobre o empenho em normas de conduta nas lições de gramática, com foco na regência verbal. In: NEVES, M. H. de M. Ensino de lingua e vivência de linguagem. Temas em confronto. São Paulo: Contexto, 2010. p. 197-224.

NOGUEIRA, J. Programa de português. Gramática. 2. ed. São Paulo: Nacional, 1944 [1943].

PEREIRA, E. C. Gramática expositiva (Adaptada ao 1은 2ำ 3o ano dos ginásios). São Paulo: Weiszflog, 1907.

PEREIRA, E. C. Gramática histórica. 9. ed. São Paulo: Nacional, 1935 [1915].

PEREIRA, E. C. Gramática expositiva (Curso elementar). 137. ed. São Paulo: Nacional, 1956 [1908]. 
RIBEIRO, J. Gramática portuguesa: 3o ano. 3. ed. Rio de Janeiro: Francisco Alves, 1889.

RIBEIRO, J. Gramática portuguesa: Curso superior. 22. ed. inteiramente refundida. Rio de Janeiro: Francisco Alves, 1933 [1889].

ROCHA LIMA, C. H. Gramática normativa da língua portuguesa. 17. ed. Rio de Janeiro: José Olimpio, 1974 [1957].

SOUSA DA SILVEIRA, A. F. Lições de português. 5. ed. Coimbra: Atlântida; Rio de Janeiro: Livros de Portugal, 1952 [1923].

SOUZA LIMA, M. P. de. Gramática portuguesa. Rio de Janeiro: José Olympio, 1945 [1937].

TORRES, A. de A. Moderna gramática expositiva da língua portuguesa. 9. ed. revista e ampliada. Rio de Janeiro: Fundo de Cultura, 1960 [1959].

Recebido em fevereiro de 2014. Aprovado em março de 2014. 